\title{
Isolated Cushing's Syndrome in Early Infancy Due to Left Adrenal Adenoma: An Unusual Aetiology
}

\author{
Deep Dutta1, Rajesh Jain1, Indira Maisnam1, Prafulla Kumar Mishra2, Sujoy Ghosh1, \\ Satinath Mukhopadhyay1, Subhankar Chowdhury1 \\ 1IPGMER \& SSKM Hospital, Department of Endocrinology \& Metabolism, Kolkata, India \\ 2IPGMER \& SSKM Hospital, Department of Paediatric Surgery, Kolkata, India
}

\begin{abstract}
Bilateral macronodular adrenocortical disease as a part of McCune Albright Syndrome (MAS) is the most common cause of endogenous Cushing's syndrome (CS) in infancy. Adrenocortical tumors causing CS in infancy are extremely rare. We report the case of a girl with CS who presented at age 4 months with obesity and growth retardation. Her 8 am paired cortisol and adrenocorticotropic hormone levels were $49.3 \mu \mathrm{g} / \mathrm{dL}$ and $<1 \mathrm{pg} / \mathrm{mL}$, respectively with non-suppressed serum cortisol ( $41 \mu \mathrm{g} / \mathrm{dL})$ on high-dose dexamethasone suppression test. Abdominal computed tomography scan demonstrated a $5.3 \times 4.8 \times 3.7 \mathrm{~cm}$ homogenous left adrenal mass with distinct borders. Laparotomy following pre-operative stabilization with ketoconazole $200 \mathrm{mg} /$ day, revealed a $7.5 \times 5 \times 4 \mathrm{~cm}$ lobulated left adrenal mass with intact capsule and weighing 115 grams. Histopathology showed small round adrenal tumor cells with increased nucleo-cytoplasmic ratio and prominent nucleoli. The cells were separated by fibrous septae without any evidence of vascular or capsular invasionfindings consistent with adrenal adenoma. On the $8^{\text {th }}$ post-operative day, after withholding hydrocortisone supplementation, the 8 am cortisol level was $<1 \mu \mathrm{g} / \mathrm{dL}$, suggestive of biochemical remission of CS. The patient improved clinically with a $7.5 \mathrm{~kg}$ weight loss over the next 3.5 months. This is perhaps the youngest ever reported infant with CS due to adrenal adenoma. Lack of clinical and biochemical evidence of hyperandrogenism as well as the benign histology in spite of the large tumor size $>7 \mathrm{~cm}$ diameter; $115 \mathrm{~g}$ ) are some of the unique features of our patient.

Key words: Cushing's syndrome, infancy, adrenal adenoma, ketoconazole

Conflict of interest: None declared Received: 30.05 .2012

Accepted: 15.07 .2012
\end{abstract}

\section{Introduction}

latrogenic hypercortisolism is the most common cause of Cushing's syndrome (CS) in infancy and childhood (1). In infants and children less than 7 years of age, adrenal tumors and predominantly malignant adrenal carcinoma constitute the most common causes of CS $(2,3)$. Endogenous CS is rare in infancy with less than 100 cases reported to date (4). Except for a few cases of adrenocortical carcinoma or unilateral adenoma (5), almost all the cases of adrenocorticotropic hormone (ACTH)independent CS in infancy have been reported to be due to bilateral macronodular adrenocortical disease encountered in cases of McCune Albright syndrome (MAS) $(6,7,8,9,10)$.

CS in infancy tends to be more severe. Typical signs associated with CS may also be absent (4). In infants, generalized obesity with growth retardation, frequently accompanied by virilization, is the most common presenting feature (11). Isolated CS without hyperandrogenism due to adrenal tumor is uncommon in children (12).

We report the case of a girl diagnosed with CS due to a huge left adrenal adenoma who had presented with generalized obesity without virilization at age 4 months. Left adrenal adrenalectomy following control of hypercortisolism with ketoconazole and clinical stabilization resulted in rapid weight loss with clinical and biochemical resolution of CS.

\section{Case Report}

A 4-month-old female infant was brought to our Endocrinology Clinic with complaints of weight gain in the past 3 
months, fever in the past 1 month, and respiratory distress in the past 5 days. The infant was born to non-consanguineous parents at term. Birth weight was $2.8 \mathrm{~kg}$. A maternal history of pregnancy-induced hypertension was reported.

\begin{tabular}{|ll|}
\hline \multicolumn{2}{|l|}{ Table 1. Biochemical findings in the patient } \\
\hline Parameter & \\
8 am cortisol $(\mu \mathrm{g} / \mathrm{dL})(5-25)$ & 49 \\
8 am ACTH $(\mathrm{pg} / \mathrm{mL})(4-20)$ & $<1$ \\
HDDST cortisol $(\mu \mathrm{g} / \mathrm{dL})$ & 41 \\
DHEA-S ( $\mu \mathrm{g} / \mathrm{dL})(3.4-123)$ & 22.53 \\
Fasting blood glucose (mg/dL) & 119 \\
Sodium (mmol/L) (135-145) & 134 \\
Potassium (mmol/L) (3.0-5.5) & 4.3 \\
Creatinine (mg/dL) (0.4-1.2) & 0.9 \\
ALT (U/L) (<35) & 112 \\
Albumin (g/dL) (3.5-5.5) & 4.2 \\
Hemoglobin (g/dL) (>11) & 14.8 \\
\hline ACTH: adrenocorticotrophic hormone, HDDST: high-dose dexamethasone \\
suppression test, ALT: alanine aminotransferase, \\
DHEA-S: dehydroepiandrosterone sulphate \\
\hline
\end{tabular}

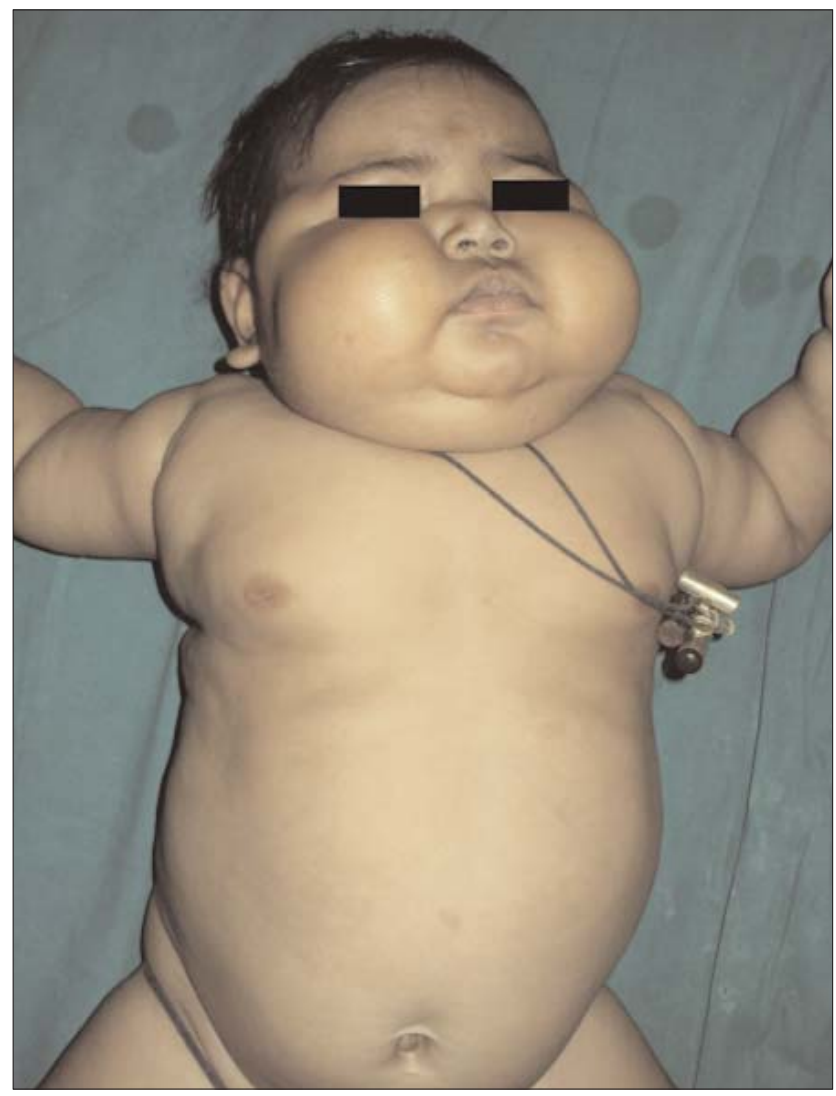

Figure 1. Profile of the patient showing chubby cheeks, moon facies and central obesity
Examination revealed a chubby baby with a moon face and a protruding abdomen (Figure 1). Striae, increased body hair, and other stigmata of MAS such as cafe au lait spots were absent. The patient's body length was $63.9 \mathrm{~cm}$ [5-10th percentile; standard deviation score (SDS):-0.9] and her weight was $15.6 \mathrm{~kg}$ (>97th percentile; SDS: +14.6). Her blood pressure was normal. Biochemical evaluation revealed a cortisol level of $49.3 \mu \mathrm{g} / \mathrm{dL}$ with a concomitant plasma ACTH level of $<1 \mathrm{pg} / \mathrm{mL}$. Her serum cortisol following high-dose dexamethasone suppression test (HDDST) [0.25 mg of dexamethasone every 6 hours for 48 hours $(20 \mu \mathrm{g} / \mathrm{kg} / \mathrm{dose})]$ was $41 \mu \mathrm{g} / \mathrm{dL}$. She had neutrophilic leucocytosis. Blood glucose was mildly elevated $(<200 \mathrm{mg} / \mathrm{dL})$, not necessitating insulin infusion (Table 1). The patient was found to have left lower lobe pneumonia. She initially received injections of ceftriaxone combined with amoxicillin-clavulanate for 6 days. Subsequently, she developed

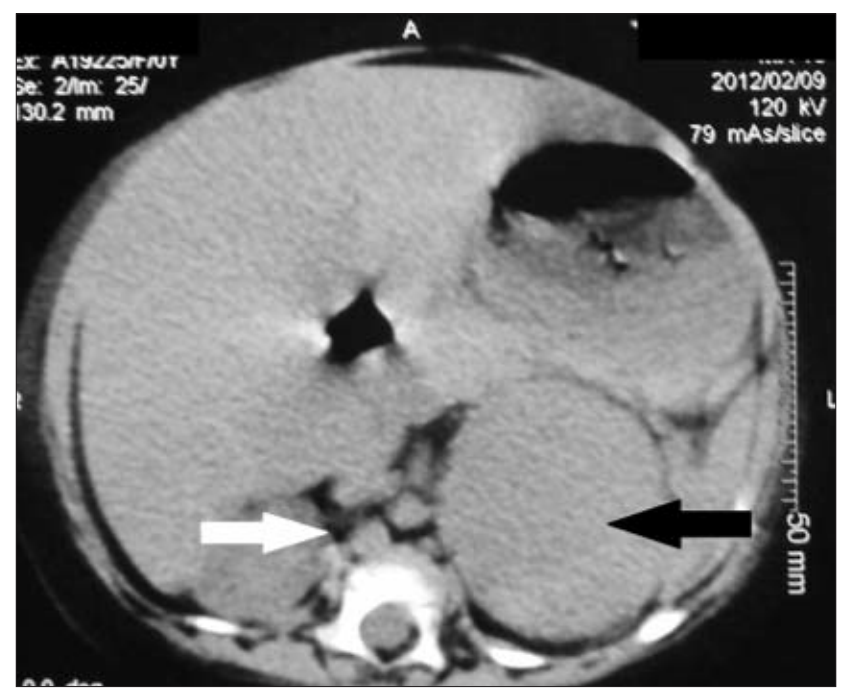

Figure 2. CT of abdomen showing homogenous left adrenal mass with distinct borders (black arrow); contra-lateral adrenal could not be visualized (white arrow)

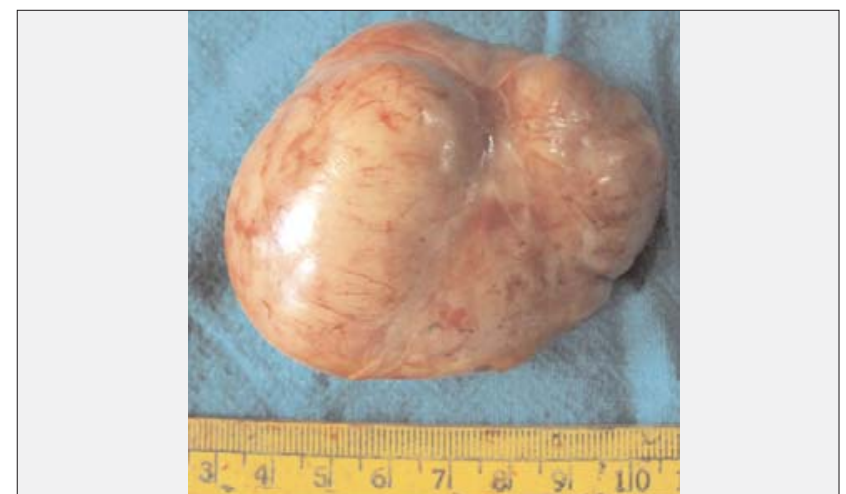

Figure 3. Surgical specimen of resected lobulated left adrenal mass with intact capsule 
diarrhea which improved with oral rehydration. The antibiotic treatment was changed to parenteral piperacillin-tazobactam $1.125 \mathrm{mg}$ thrice a day which she received for 16 days. An abdominal computed tomography (CT) (non-contrast) revealed a $5.3 \times 4.8 \times 3.7 \mathrm{~cm}$ homogenous left adrenal mass with distinct borders. The right adrenal was not visualized (Figure 2). Ketoconazole was started at $200 \mathrm{mg} /$ day in 2 divided doses. Laparotomy following resolution of pneumonia and clinical stabilization revealed a $7.5 \times 5 \times 4 \mathrm{~cm}$ lobulated left adrenal mass with an intact capsule and weighing $115 \mathrm{~g}$ (Figure 3). The inferior vena was spared; there was no lymphadenopathy or adhesions to adjacent organs. Histopathology revealed findings suggestive of adrenal adenoma: small round adrenal tumor
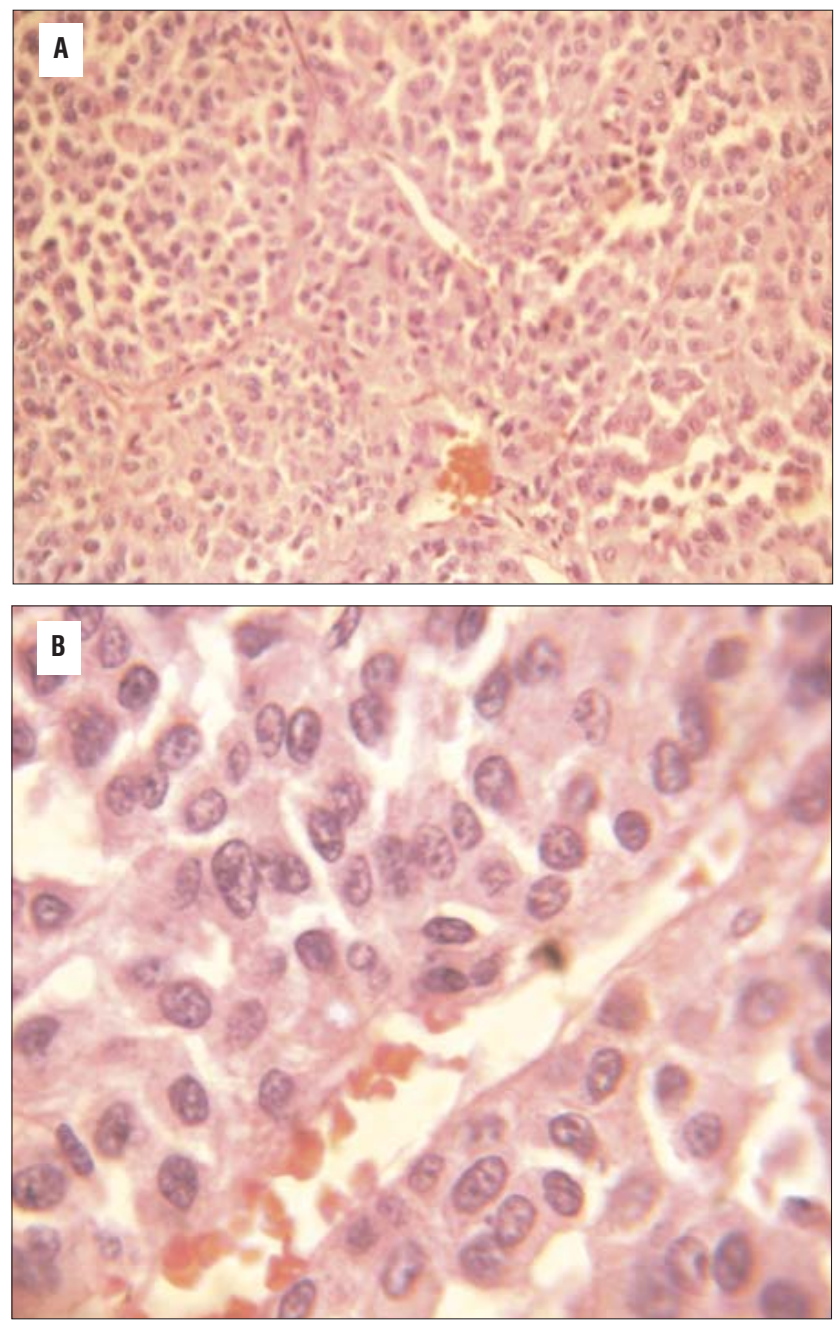

Figure 4a. Eosin and hematoxylin staining of adrenal adenoma (40X magnification) showing small round adrenal tumor cells with prominent nuclei and nucleoli, bands of fibrous septae separating the tumor cells, without evidence of vascular invasion; Figure 4b: High magnification (100X) showing blue round adrenal cells with increased nucleo-cytoplasmic ratio and prominent nucleoli and no evidence of vascular invasion cells separated by fibrous septae and with increased nucleocytoplasmic ratio, prominent nucleoli, without any evidence of vascular or capsular invasion (Figure 4).

Post-operatively, the patient received IM hydrocortisone 25 mg 6-hourly for 2 days followed by tapering and shifted to

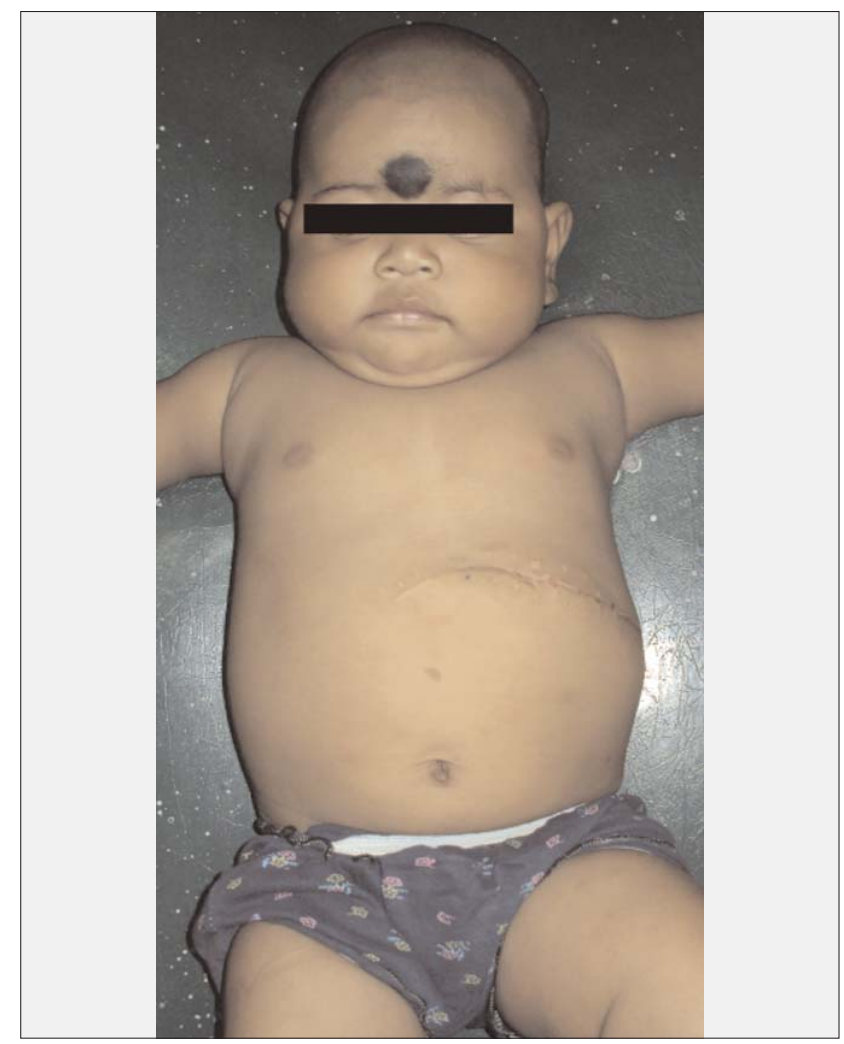

Figure 5. Profile of the patient at 3 months post-operative showing significant weight loss and resolution of features of Cushing's syndrome

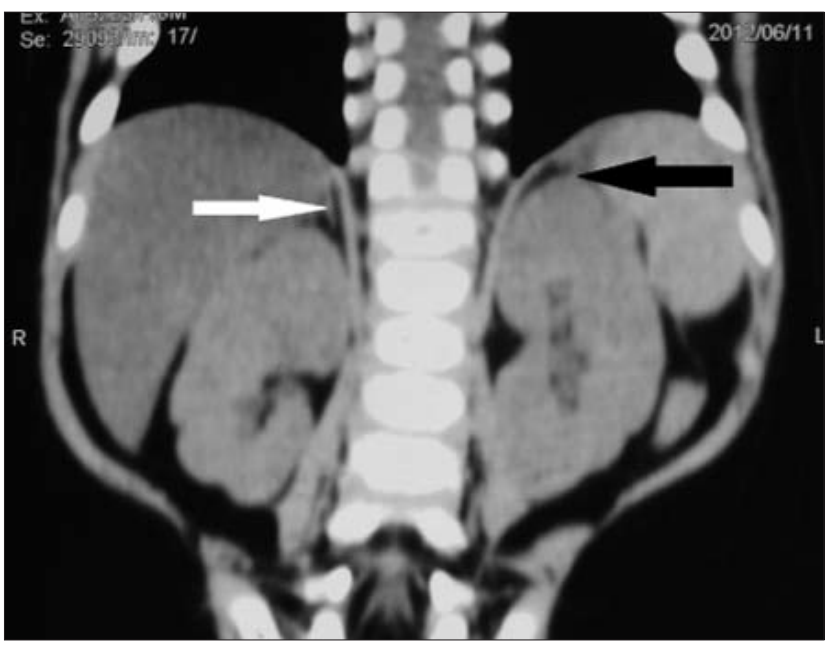

Figure 6. Post-operative ( 3 months) imaging showing absence of left adrenal (removed) (black arrow) and reappearance of one of the limbs of the right adrenal gland (white arrow) 
Dutta D et al.

Cushing's Syndrome in Infancy

an oral replacement dose of $10 \mathrm{mg}$ in the morning and $5 \mathrm{mg}$ in late afternoon. She also received fludrocortisone $50 \mu \mathrm{g} /$ day in the first 4 post-operative days. The patient's blood glucose level normalized by the $4^{\text {th }}$ post-operative day. On the $8^{\text {th }}$ post-operative day, after withholding the late afternoon dose of hydrocortisone the previous day and prior to the administration of the morning hydrocortisone dose, the $8 \mathrm{am}$ cortisol blood level was $<1 \mu \mathrm{g} / \mathrm{dL}$, and was suggestive of biochemical remission of CS. The patient was discharged on post-operative day 14 . She had lost significant amount of weight and had reached a weight of $9.6 \mathrm{~kg}$. The hydrocortisone dose was tapered to $5 \mathrm{mg}$ in the morning and $2.5 \mathrm{mg}$ in the late afternoon at 2 months of follow-up when her 1-hour post ACTH (250 $\mu \mathrm{g}$ IM) cortisol level was 6.9 $\mu \mathrm{g} / \mathrm{dL}$ (after withholding the previous evening and the same day morning dose of hydrocortisone). Last evaluated three and half months after the surgery, the patient was found to have lost more weight (weight at evaluation: $8.1 \mathrm{~kg}$ ) with resolution of clinical features of CS (Figure 5). Adrenal imaging at this time was normal (Figure 6). Hydrocortisone was stopped with counselling for stress coverage of hydrocortisone as her post ACTH cortisol (using the same protocol) was $10.1 \mu \mathrm{g} / \mathrm{dL}$.

\section{Discussion}

In this paper, we present an infant with CS who had a large unilateral (left) adrenal mass. Pediatric adrenocortical tumors (ACTs) are rare in infancy and occur primarily in children between one to five years of age $(60 \%)$, with a peak in incidence below 4 years of age ( 0.4 cases per million). Nearly half of these ACTs are adrenocortical carcinoma (2). In a registry of 254 pediatric patients with $\mathrm{ACTs}, 55 \%$ presented with virilization alone. Only $5.5 \%$ of the children in this registry had isolated $\mathrm{CS}$, and this tended to occur in older children (median age, 12.6 years) (13). Increased androgen production in infancy and early childhood ACTs can be explained by the structure of the adrenal gland at birth. At this time, the inner fetal zone constitutes $85-90 \%$ of the gland; the primary steroid product of the inner fetal zone is dehydroepiandrosterone sulphate (14).

Our infant presented with isolated CS without any clinical or biochemical evidence of hyperandrogenism, which is rare. To the best of our knowledge, CS due to adrenal adenoma presenting early in infancy has not been reported previously. Also intriguing is the benign nature of the tumor despite its large size. To control the profound hypercortisolemic state and thus reduce the peri-operative morbidity and mortality, ketoconazole was administered to our patient pre-operatively.
Ketoconazole is an imidazole derivative, originally used as an anti-fungal drug but is one of the most commonly used drugs in the medical management of both Cushing's disease and CS, as well as in preparing these patients for surgery (15). Ketoconazole inhibits several steps of adrenal steroidogenesis including the cholesterol side-chain cleavage enzyme, 17 $\alpha$-hydroxylase and 17,20-lyase, thus has a beneficial effect in CS. In addition, it has a direct inhibitory effect on ACTH release from the pituitary $(15,16)$. In adults, ketoconazole is used in doses of 400-1200 mg/day in divided doses (15). Common side effects are gastrointestinal upset and skin rash. Liver dysfunction in the form of mild reversible increase in transaminase levels can occur in about $10 \%$ of the patients (17). However, serious hepatic injury is rare and can rarely be fatal $(17,18)$.

Post-operative hydrocortisone supplementation following surgery for adrenal adenoma causing CS is necessary as the contralateral adrenal gland is usually hypoplastic secondary to prolonged suppressed ACTH secretion from the pituitary due to CS. This explains the lack of visualization of the contralateral adrenal in our patient and the adrenal insufficiency state documented on the $8^{\text {th }}$ post-operative day.

From the registry of a series consisting of 254 pediatric ACTs, those with completely resected tumors weighing less than $200 \mathrm{~g}$ and without metastasis had a five-year event-free survival rate of $91 \%$. Age less than four years was independently associated with better prognosis. A multivariate analysis showed an adjusted odds ratio of 2.6 for patients aged less than four years (13). Complete biochemical resolution of hypercortisolism post-operative with favorable histological features is probably predictive for a good prognosis in our patient.

To summarize, our patient who presented at age 4 months with obesity and growth retardation is possibly the youngest ever reported case of CS due to adrenal adenoma. Surgical removal of the mass resulted in rapid weight loss with biochemical and clinical resolution of CS.

\section{References}

1. Migeon CJ, Lanes R. Adrenal cortex: Hypo and hyperfunction. In: Fima Lifshitz Pediatric Endocrinology, 5th ed Informa Healthcare, 2007; 8: 214.

2. Miller WL, Townsend JJ, Grumbach MM, Kaplan SL. An infant with Cushing's disease due to an adrenocorticotropin-producing pituitary adenoma. J Clin Endocrinol Metab 1979; 48:1017-1025.

3. Loridan L, Senior B. Cushing's syndrome in infancy. J Pediatr 1969; 75:349-359.

4. Gunther DF, Bourdeau I, Matyakhina L, Cassarino D, Kleiner DE, Griffin K, Courkoutsakis N, Abu-Asab M, Tsokos M, Keil M, Carney JA, Stratakis CA. Cyclical cushing syndrome presenting in infancy: An early form of primary pigmented nodular adrenocortical disease, or a new entity? J Clin Endocrinol Metab 2004; 89:3173-3182. 
Dutta $D$ et al.

Cushing's Syndrome in Infancy

5. Gessler P, Ranke MB, Wollmann H, Aicher KP, Feine U, Kaiserling E, Leriche C, Steil E. Adrenocortical nodular hyperplasia as a cause of Cushing syndrome in the neonatal period. Klin Padiatr 1991;203:462-466.

6. Boston BA, Mandel S, LaFranchi S, Bliziotes M. Activating mutation in the stimulatory guanine nucleotide-binding protein in an infant with Cushing's syndrome and nodular adrenal hyperplasia. J Clin Endocrinol Metab 1994;79:890-893.

7. Davies JH, Barton JS, Gregory JW, Mills C. Infantile McCuneAlbright syndrome. Pediatr Dermatol 2001;18:504-506.

8. Kirk JM, Brain CE, Carson DJ, Hyde JC, Grant DB. Cushing's syndrome caused by nodular adrenal hyperplasia in children with McCune-Albright syndrome. J Pediatr 1999;134:789-792.

9. Danon M, Robboy SJ, Kim S, Scully R, Crawford JD. Cushing syndrome, sexual precocity, and polyostotic fibrous dysplasia (Albright syndrome) in infancy. J Pediatr 1975;87:917-921.

10. Aarskog D, Tveteraas E. McCune-Albright's syndrome following adrenalectomy for Cushing's syndrome in infancy. J Pediatr 1968;73:89-96.

11. Cushing Syndrome. In: Kliegman RM, Behrman RE, Jenson $H B$, Stanton BF. Nelson Textbook of Pediatrics, $18^{\text {th }}$ ed Saunders 2007; 578:2369.
12. Adrenal tumors. In: Kliegman RM, Behrman RE, Jenson HB, Stanton BF. Nelson Textbook of Pediatrics, 18th ed Saunders 2007; 580:2372.

13. Michalkiewicz E, Sandrini R, Figueiredo B, Miranda EC, Caran E, Oliveira-Filho AG, Marques R, Pianovski MA, Lacerda L, Cristofani LM, Jenkins J, Rodriguez-Galindo C, Ribeiro RC. Clinical and outcome characteristics of children with adrenocortical tumors: a report from the international pediatric adrenocortical tumor registry. J Clin Oncol 2004;22:838-845.

14. Coulter CL. Fetal adrenal development: insight gained from adrenal tumors. Trends Endocrinol Metab 2005;16:235-242.

15. Sonino N, Boscaro M, Paoletta A, Mantero F, Ziliotto D. Ketoconazole treatment in Cushing's syndrome: experience in 34 patients. Clin Endocrinol (Oxf) 1991;35:347-352.

16. Tabarin A, Navarranne A, Guérin J, Corcuff JB, Parneix M, Roger $P$. Use of ketoconazole in the treatment of Cushing's disease and ectopic ACTH syndrome. Clin Endocrinol (Oxf) 1991;34:63-69.

17. Lewis JH, Zimmerman HJ, Benson GD, Ishak KG. Hepatic injury associated with ketoconazole therapy. Analysis of 33 cases. Gastroenterology 1984;86:503-513.

18. Zöllner E, Delport S, Bonnici F. Fatal liver failure due to ketoconazole treatment of a girl with Cushing's syndrome. J Pediatr Endocrinol Metab 2001;14:335-338. 